\title{
Las prácticas de sí en la pedagogía de Vives, Comenio, Pestalozzi y Dewey \\ y su reemergencia contemporánea en las escuelas*
}

\section{Artículós te Educación, N. ${ }^{\circ} 65$. Segundo semestre de 2013 Bogotá, Colombia.}

//The practices of self in the teaching of
Vives, Comenio, Pestalozzi and Dewey and
their contemporary reemergence in schools

\section{//As práticas de si na pedagogia de Vives, Comenius, Pestalozzi e Dewey e a sua re- emergência contemporânea nas escolas}

\author{
Javier Saenz Obregón**
}

Recibido: 10/07/2013 Evaluado: 22/09/2013

\footnotetext{
* Este escrito es resultado del proyecto de investigación Estudio crítico de algunas prácticas de sí contemporáneas, auspiciado por la Facultad de Ciencias Humanas de la Universidad Nacional de Colombia y realizado bajo la dirección del autor por el grupo de investigación Gobierno, subjetividades y Prácticas de Sí, del Centro de Estudios Sociales de la universidad.

** Javier Sáenz Obregón es Ph.D en Historia y Filosofía de la Educación, Institute of Education, University of London. Profesor titular Departamento de Sociología e investigador Centro de Estudios Sociales de la Universidad Nacional de Colombia. Correo electrónico: jsaenzo@unal.edu.co
}

\section{Resumen}

El texto rastrea la forma como las prácticas de sí, constitutivas de la escuela, perdieron su centralidad en el discurso pedagógico de Comenio, desaparecieron en el de Pestalozzi y fueron atacadas como peligrosas en el discurso de Dewey. Tales prácticas formaron parte de un conjunto más amplio en donde se localizan las prácticas de cortesía de la aristocracia, las prácticas de saber de las universidades, las prácticas de gobierno y auto-gobierno cristiano de los monasterios, entre otras, y contribuyeron a ensamblar la escuela y la pedagogía desde el siglo $X V$. Su examen relaciona sus transformaciones con las de las concepciones del sujeto, la verdad, la moral, los fines de la educación, y las prácticas de saber y gobierno de la escuela. Interroga, por último, el sentido de la reemergencia reciente de las prácticas de sí en la escuela.

\section{Abstract}

This text examines how practices of the self, after being part of a set of practices that schools have appropriated since the 15th century (such as aristocratic courtesy, knowledge practices at university, practices of Christian governance and self-governance), lost their centrality in the pedagogical discourse of Comenius, disappeared in that of Pestalozzi, and were attacked as dangerous in the pedagogical discourse of Dewey. The transformations in these practices are linked with those of conceptions of the subject, truth, morality, the aims of education and practices of knowledge and government in schools. The text also examines the meaning of the recent re-emergence of practices of the self in schools.

\section{Resumo}

O texto examina a forma como as práticas de si, constitutivas da escola, perderam a sua centralidade no discurso pedagógico de Comenius, desapareceram no discurso de Pestalozzi e foram sinaladas como perigosas no discurso de Dewey. Tais práticas formaram parte de um conjunto mais abrangente onde se localizam as práticas de cortesia da aristocracia, as práticas de saber nas

\section{Palabras Clave}

Prácticas de sí, pedagogía, auto-coacciones, gobierno, saber.

\section{Keywords}

Practices of the self, pedagogy, coactions, government, knowledge.

\section{Palavras chave}

Práticas de si, pedagogia, autocoações, governo, saber. 
universidades, as práticas de governo e autogoverno cristão nos mosteiros, entre outras, e contribuíram a ajeitar a escola e a pedagogia desde o século XV. Seu exame relaciona as suas transformações com aquelas sofridas pelos conceições de sujeito, verdade, moral, fins da educação e práticas de saber e governo da escola. Interroga, por último, o sentido da re-emergência recente das práticas de si na escola.

Este escrito se fundamenta en un estudio histórico sobre el discurso pedagógico y sus efectos en la constitución del sujeto moderno entre los siglos XVI y XX y de un proyecto de investigación sobre la genealogía y las prácticas de sí contemporáneas. Se basa en el examen del discurso pedagógico de los escritos de Juan Luis Vives, Jon Amos Comenius, Johann Heinrich Pestalozzi y John Dewey'.

El artículo se concentra en las prácticas de gobierno, definidas por Foucault como "técnicas y procedimientos para dirigir la conducta humana" (2000a: p. 81), las cuales "persiguen un equilibrio siempre difícil y versátil, con conflictos y complementariedades, entre las técnicas que aseguran la coerción y los procesos mediante los cuales el yo es construido y modificado por sí mismo" (Foucault, citado por Morey, 1996, p. 34). Este gobierno incorpora dos tipos de prácticas claramente diferenciadas: prácticas de poder, definidas como "los métodos y técnicas usados en distintos contextos institucionales para actuar sobre la conducta de los individuos, tomados de manera separada o en grupo, para moldear, dirigir o modificar la forma de conducirse a sí mismos" (Foucault, 2000b, p. 463) y prácticas de sî:

Que permiten a los individuos llevar a cabo por sus propios medios, o con la ayuda de otros, un cierto número de operaciones sobre sus cuerpos o almas, pensamiento, conducta y forma de ser, para transformarse a sí mismos y así lograr cierto estado de felicidad, pureza, sabiduría, perfección o inmortalidad (Foucault, 2000c, p. 225).

1 Los textos pedagógicos examinados fueron publicados por Vives entre 1524 y 1538; los de Comenio, entre 1631y 1658; los de Pestalozzi, entre 1781 y 1826; y los de Dewey, entre 1882 y 1948. La conceptualización del problema y su abordaje se fundamentan, principalmente, en tres fuentes: las reflexiones sobre la historicidad de la pedagogía de Olga Lucía Zuluaga (1987) y del grupo de Historia de la Práctica en Colombia, las conceptualizaciones de Michel Foucault sobre la genealogía y las prácticas de saber, poder y prácticas de sí y el concepto de Norbert Elías (1994) sobre el proceso civilizatorio.

2 Foucault también se refiere a ellas como técnicas de sí y algunas traducciones al español las nombran como tecnologías del yo. 
Se trata de prácticas deliberadas que permiten que el individuo se constituya en un sujeto ético por medio de su autotransformación (Foucault, 1992, p. 29).

Para Foucault (2000d, pp. 263265), esta relación consigo mismo tiene cuatro dimensiones centrales: las fuerzas del sujeto, que han de convertirse en objeto de la práctica, la manera en que los individuos son conducidos a emprender las prácticas sobre sí, las técnicas específicas (o medios) por medio de las cuales los sujetos actúan sobre sí y el tipo de sujeto al cual pueden aspirar por medio de estas prácticas. En el transcurso del proyecto cuyos resultados recoge este capítulo se elaboró una rejilla de análisis de las prácticas de sí, en la cual se incorporaron otras dimensiones para examinar estas prácticas (Sáenz, 2010). Entre estas, las que se retoman en este escrito son las dimensiones referidas a aquellas fuerzas del sujeto que actúan como agente de las acciones sobre sí, las concepciones sobre la naturaleza o forma del sujeto $^{3}$, y las relaciones que se establecen entre las prácticas de sí, la verdad y las prácticas de saber ${ }^{4}$ y poder.

3 Mientras que las otras dimensiones añadidas provienen de otros escritos de Foucault, estas dos no fueron desarrolladas por el autor de este artículo.

4 Las prácticas de saber abarcan "los mecanismos e instancias que hacen posible distinguir entre proposiciones verdaderas y falsas, los medios a través de los cuales cada una es sancionada; las técnicas y procedimientos valoradas en la adquisición de la verdad; el estatuto de quienes son encargados de establecer que es verdad" (Foucault, 1977, p. 120). Lejos de estar por encima de las relaciones de poder, las prácticas

\section{Vives: el sujeto como campo de batalla}

Desde la invención de la escuela en el siglo XV y el primer tratado comprehensivo para estas escuelas, De Disciplinis de Vives (1531), las prácticas de sí fueron asunto central de las prescripciones pedagógicas. Hay algunas pistas de que las primeras escuelas, en el sentido moderno del término (con ocho o más grados diferenciados por edades, con un maestro para cado grado, con asistencia permanente durante varias horas del día y durante la mayoría del año), fueron las de los Hermanos de la Vida en Común en el siglo XV en Alemania y los Países Bajos, que incorporaron las prácticas de sí del monacato cristiano (Hyma, 1965) ${ }^{5}$. A través de estas prácticas, el poder pastoral del cristianismo institucional se volvió omnipresente y buscó

de saber producen efectos en estas relaciones y están inscritas en sistemas de poder. Las relaciones de poder no solo censuran, bloquean o reprimen: producen efectos a nivel de los deseos y del saber; no solo previenen, sino que producen saber (Foucault, 1977). Como lo ha señalado Zuluaga, en las escuelas, estas prácticas de saber adquieren altos niveles de regulación y formalización, pues el propósito central de las escuelas ha sido "la circulación, difusión, producción, moldeamiento y distribución del saber" (Zuluaga, 1987, p. 195).

5 Fueron los Hermanos de la Vida en Común quienes escribieron La imitación de Cristo, texto prescriptivo sobre prácticas de sí con un enorme impacto en Occidente y las sociedades occidentalizadas. Mientras que comúnmente se le atribuye a Thomas a Kempis (alumno en una escuela de los Hermanos), Joseph Malaise (1988) se lo atribuye a Gerard Groote, fundador de esta congregación.

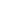


gobernar a maestros y alumnos en todos los espacios y tiempos, y no solo en el escenario escolar.

La estrategia central de las prescripciones de Vives en el combate por la salvación cristiana del alma era una serie de prácticas para el cultivo del autoconocimiento y el autocontrol que tenían como fin el establecimiento de una relación correcta con Dios, la verdad y los otros (Vives, 1968, pp. 111 y 158). El autoconocimiento implicaba una vigilancia constante por parte del alumno de sus acciones, pasiones, pensamientos y apetitos carnales. Por medio del autoexamen el alumno debía meditar de manera permanente sobre cómo pensar, hablar y actuar correctamente, y sobre la pecaminosidad de los apetitos de la carne (Vives, 1968, pp. 92, 109, 114 y 158). Para la concepción institucionalmente cristiana de Vives, cuando el sujeto miraba hacia adentro, se encontraba con el más poderoso de los aliados; Dios como un testigo permanente que se manifestaba como la conciencia interna que debía ser obedecida (Vives, 1968, pp. 154 y 157 y 1913, pp. 84-85). El autoconocimiento, entonces, era un examen de las disposiciones personales para alinearlas con Dios y su ley moral. No era un fin en sí mismo, sino el medio para un control eficaz de las tendencias malignas y el cultivo de sentimientos virtuosos (Vives, 1968, p. 116). Los alumnos debían autocontrolarse tanto en la intimidad de su ser como en su conducta hacia los otros: el cuerpo debía obedecer a la mente; "los impulsos no racionales de la mente" debían obedecer a la razón; y las pasiones tenían que ser "controladas, sanadas, desechadas" (Vives, 1913, pp. 84, 232-233 y 250).

A través del acatamiento de las normas de la cortesía, concebidas como un anillo defensivo protector de la virtud, se prescribía que los alumnos suprimieran la expresión externa de las pasiones. El habla del alumno tenía que ser cortés y moderada. Los gestos de la cara y de todo el cuerpo tenían que ser controlados para que comunicaran "solo aquella quietud y serenidad que comprueba el control de las pasiones". Se aconsejaba evitar la risa frecuente e inmoderada. Los alumnos debían cultivar una disposición de especial humildad y obediencia hacia aquellos con autoridad (Vives, 1968, pp. 138-142). El cuerpo tenía que ser controlado de manera severa, y se le debía prestar especial atención a evitar los placeres y deseos de la carne pecaminosa (Vives, 1968, pp. 88, 96-98 y 100 y Vives, 1913, p. 176).

Los alumnos eran conducidos a cultivar deseos, sentimientos y disposiciones virtuosas hacia Dios, los otros y sí mismos. 
Debían cultivar el amor, la reverencia y el temor hacia Dios (Vives, 1913, pp. 84 y 116) ${ }^{6}$. El desagrado hacia el pecado se obtenía por medio del reconocimiento de la maldad en uno mismo, el arrepentimiento y el cultivo de sentimientos de culpa y vergüenza (Vives, 1968, p. 108 y 1913, pp. 153-154 y 255256). También debía cultivarse un amor autosacrificador, espiritual y caritativo (Vives 1948, p.1206). Más que por medio de la instrucción, en el discurso de Vives, la verdad depende de la disciplina de estudio del alumno. Estudio y autodisciplina eran sinónimos; el conocimiento no era, como lo sería más adelante en la pedagogía, el resultado de un método de conocimiento. Implicaba una doble disciplina; la purificación y la pacificación del alma para la recepción correcta de las verdades transmitida, y la correcta transposición del conocimiento en acciones.

\section{Comenio: hacia la producción metódica de la virtud}

Si bien las prácticas de sí también hicieron parte de las prescripciones de la pedagogía de Comenio, dejaron de ocupar un lugar tan central, y hubo un mayor énfasis sobre las prácticas hacia los demás y hacia el mundo. En comparación con Vives,

6 Esta particular mixtura entre amor y temor constituyó una discontinuidad radical con Séneca, para quien "ser verdaderamente respetado es ser amado; el amor y el temor no pueden convivir" (1969, p. 95). se movió el centro de gravedad de las prácticas de gobierno hacia la dimensión pública y política de las acciones, por medio de la inclusión de un nuevo grupo de virtudes, tales como la liberalidad, la justicia y la sociabilidad. Comenio también subrayó la virtud de la diligencia, relacionada con el trabajo (1986, p. 62).

Uno de los acontecimientos más significativos de la pedagogía de Comenio fue la separación entre prácticas morales y religiosas, estas últimas referidas a la virtud y la piedad. Las prácticas para el logro de la virtud se ocupaban de la relación del sujeto consigo mismo, y las morales se dirigían a las obras externas, definidas en relación con los otros (Comenio, 1907, p. 113). Mientras que en Vives -como en las artes de la existencia de las sectas filosóficas helenísticas- actuar sobre sí iba de la mano de actuar correctamente sobre los otros, en el discurso de Comenio, las acciones directas sobre sí se circunscribieron al cultivo de la piedad: al establecimiento de una relación correcta con Dios, eso es, con la interioridad.

Hubo otros cambios en relación con el discurso de Vives. En primer lugar, las afecciones morales hacia los otros fueron concebidas más como un efecto sobre los alumnos de las acciones metódicas del maestro y la máquina escolar (el orden metódico de organización de la enseñanza y la disciplina), que ya no como resultado de una autodisciplina moral voluntaria de autotransformación. En segundo lugar, se dio un 
giro: de la preocupación central de Vives con el control de las pasiones hacia una mayor atención al control de las imágenes mentales y los pensamientos. En tercer lugar, las prácticas de sí se inscribieron en una estrategia de prescripciones metódicas precisas (eso es, la metodización de lo que en Vives tenia más la forma de un arte): el autoconocimiento debía ser practicado primero, luego el autogobierno y por ultimo el yo debía dirigirse hacia Dios (Comenio, 1907, p. 36). Las acciones internas del sujeto preparaban para la unión con Dios por medio de obediencia incondicional y el cultivo del amor y el deseo por Dios, (pp. $218-219$ y 225) y la rendición a su amor por medio del examen en el progreso de la piedad por medio de la oración, entendida como un deseo permanente hacia Dios; y la meditación: "la constante, atenta y devota contemplación de las obras, las palabras y la bondad de Dios" (p. 219).

También hubo transformaciones en cómo el alumno debía practicar el autocontrol. De una parte, un nuevo énfasis en armonizar las pasiones y los deseos con la virtud (p. 76), más que, como en Vives, sobre su derrota y supresión. De otra parte, por medio del ejercicio de un estricto control sobre las imágenes sensoriales y las ideas que no condujeran a la virtud o la verdad'. Y, por último, un distanciamiento de las formas directas de Vives hacia formas indirectas de controlar los movimientos viciosos del yo.

Finalmente, mientras que los sentimientos virtuosos de temor y amor a Dios debían ser cultivados por el alumno por medio de "una piedad interna y ferverosa"; las afecciones morales, tales como el amor al conocimiento, el desagrado hacia el pecado y el sentimiento de vergüenza que debía acompañar las acciones inmorales, debían ser producidas por las acciones del maestro, el método y el orden de las escuelas (Comenio, 1956, pp. 102; 1986, p. 150; 1907, pp. 74 y 126; Komensky, 1953, p. 126).

\section{Pestalozzi: autodependencia y moralidad involuntaria}

En el discurso de Pestalozzi desaparecieron las prescripciones explícitas sobre cómo los alumnos debían actuar sobre sí. El yo interno se había convertido en una entidad natural, libre y espontánea

7 Ver Comenius, 1986, p. 149 y Komensky, 1953, p. 182. Como lo ha señalado Foucault, el filósofo estoico Epicteto prescribía una vigilancia constante sobre pensamientos y representaciones mentales indeseables, que para los estoicos era una forma de comprobar la independencia del individuo en relación con el mundo (Foucault 2000c, p. 240.). 
que no necesitaba que se actuara sobre ella. Las prácticas pedagógicas, por tanto, debían volverse naturales, en el sentido de fundamentarse en este yo interno idealizado.

Apareció entonces un nuevo tipo de relación entre moralidad (entendida, a diferencia de Comenio, tanto como relación con Dios y con los otros), libertad, y la naturaleza voluntaria-involuntaria de las acciones; una relación que recurriría en la pedagogía de Dewey y en las apropiaciones pedagógicas de la psicología conductista. Mientras que tanto Vives como Comenio estaban cercanos a la noción aristotélica según la cual para que una acción fuese virtuosa, el individuo debía saber que lo era (Aristóteles, 1988), el discurso de Pestalozzi puede ser caracterizado como de moralidad involuntaria. La moralidad se había convertido en un efecto indirecto de ciertas formas de actuar sobre el mundo y relacionarse con los demás, de cuyas consecuencias morales el alumno no tenía que percatarse y, para Dewey, era mejor que no lo hiciese. Igualmente, en la pedagogía de Pestalozzi hubo un giro en la concepción de la libertad: del dogma cristiano sobre la libertad de la voluntad al margen de las circunstancias, hacia la noción que la libertad era algo a ser logrado por medio de la dependencia total en el yo interno y natural; un estado de existencia que liberaba al yo de la sospechosa moralidad de las convenciones sociales.

En la pedagogía de Pestalozzi se presentó otro movimiento de prácticas morales directas hacia formas indirectas de producir moralidad: el yo interno se descubría por medio de acciones metódicas y naturales de saber y por medio de la amorosa, inconsciente y libre rendición de la voluntad del alumno a aquella del maestro. La moralidad se había convertido en una relación correcta con el mundo y con los otros y había dejado de ser una forma de relacionarse deliberadamente con uno mismo.

Hubo un giro, significativo y extraño en el discurso de Pestalozzi que es característico del pensamiento de la Ilustración: mientras que colocaba la autodependencia (autonomía, la autarkeia de las sectas filosóficas griegas y romanas) en un lugar central, excluía aquellas prácticas directas del individuo sobre sí que habían sido centrales, en versiones radicalmente diferenciadas, en la constitución de un sujeto ético desde la Grecia antigua. El alumno dejó de ser un sujeto en relación consigo mismo y quedó solo como sujeto en relación con el mundo natural y los otros.

Para Pestalozzi, el autoconocimiento y el conocimiento del mundo eran los medios para el reconocimiento de Dios y la ley moral (Pestalozzi, 1907, p. 196). Por medio de una instrucción directa y usando sus capacidades individuales el alumno llegaba a reconocer "sus capacidades y poderes en toda su variedad -física, intelectual, estética, moral, religiosa-" (Pestalozzi, 1913, p. 339). En discontinuidad con el discurso pedagógico anterior, el 
autoconocimiento no era una práctica de autoobservación y autoexamen, sino el reconocimiento, posibilitado por una pedagogía natural, de los poderes del individuo de actuar sobre el mundo y los otros. Igualmente, los sentimientos religiosos-morales innatos se desenvolvían en el individuo como efecto indirecto de las acciones y reacciones del alumno hacia el amor estratégico del maestro, que no por medio de su cultivo directo (Pestalozzi, 1931 , p. 37 y 1907, pp. 188-189, 194-195 y 211).

El autocontrol se convirtió también en un efecto indirecto de las prácticas del alumno: de la rendición de su voluntad a la del maestro, de sus relaciones con otros alumnos, de la disciplina y las formas naturales de aprender. Por medio de estas prácticas, el alumno desarrollaba el hábito (autocoacción automática e inconsciente en términos de Norbert Elías, 1994) de autonegación, de supresión de deseos corruptos y de pensamientos y habla innecesaria (Pestalozzi, 1827, p. 67). El método natural de aprender disciplinaría el pensamiento de los alumnos de tal forma que no permitiría la aparición de un pensamiento libre; o de un pensamiento meramente curioso, que no era considerado ni moral ni verdadero (Pestalozzi, 1907, p. 82 y 1982, pp. 53-54).

\section{Dewey: los peligros sociales de ocuparse de sí}

En el discurso pragmatista de Dewey las prácticas de sí fueron atacadas como peligrosas para la formación de un individuo social, saludable, democrático y productivo. Mientras que en Vives, Comenio y Pestalozzi la virtud implicaba un desapego del yo de una colectividad corrupta y una dependencia con fuentes internas de moralidad; para Dewey, ser moral significaba algo radicalmente opuesto: se trataba de conectar el yo con esfuerzos colectivos para superar una preocupación de sí, ahora considerada como escapista y egoísta. Para Dewey, "el individuo desconectado de su situación social" era "éticamente irreal" (1977a) ${ }^{8}$. Enfatizó el poder moral de la interdependencia y creía que el aumento en la independencia individual -en la autodependencia o la autosuficiencia- portaba el peligro de disminuir la capacidad social del individuo, haciéndolo insensible e indiferente hacia los otros" (p. 44).

8 Debe subrayarse que mi análisis del discurso de Dewey se circunscribe a sus escritos pedagógicos. Es posible encontrar un discurso menos dogmáticamente social en sus otros escritos. 
Por medio de la oposición que estableció entre ocuparse de sí y ocuparse de los otros (1977b, p. 277), Dewey separó, de una manera radicalmente distinta a la que ya lo había hecho el cristianismo institucional, lo que la filosofía helenística había considerado inseparable. La sociabilidad, entendida por Dewey como una apertura empática hacia los otros y hacia la dimensión colectiva de la vida, se convirtió en la condición indispensable para la constitución de un yo moral (Dewey, 1972 , p. 80; 1977b, pp. 288-289 y 1997, pp. 50, 121 y 244). Aquellos individuos que, a cambio de actuar deliberada, metódica e inteligentemente sobre el mundo, devolvían hacia sí sus sentimientos e ideas, se convertirían en escapistas que se refugiarían "en un juego interno de sentimientos y fantasías"; se convertirían en gozadores excéntricos, sentimentales y auto-indulgentes de sus propias fantasías y emociones (Dewey, 1997, pp. 135-136).

El giro central del discurso de Dewey fue hacia la formación de un yo moral, extravertido y social. Su discurso moral tenía una obsesión central: refutar lo que había sido el precepto central del discurso pedagógico cristiano: que la moralidad era primordialmente un asunto individual que se encontraba en el yo interno. Atacó esta concepción desde distintas posiciones. En términos políticos, creía que sustentaba la filosofía de los reaccionarios -tanto de los conservadores como del liberalismo individualista y de laissez-faire- y era la producción histórica de arreglos sociales no democráticos, en los cuales ocuparse de sí había sido un lujo de las clases dominantes, entre las cuales incluía a los monjes. Desde una perspectiva económica este individualismo iba en contra de la naturaleza cooperativa de las prácticas productivas contemporáneas, y contra el bienestar social y el progreso. Desde una perspectiva médico-psiquiátrica creía que ocuparse de sí era patológico: producía individuos desadaptados, incapaces de relacionarse con lo social. Que el alumno se ocupara de sus propios pensamientos, emociones e instintos era la vía hacia la locura; era la negación de la irrealidad del yo por fuera de las interacciones sociales. Si con Vives, las cosas del mundo tendían a tener una existencia ilusoria y frágil, ocultas como estaban entre Dios y la palabra sagrada, para Dewey eran las cosas internas -eso es, los objetos de la autopercepción- las que eran irreales.

Como en Pestalozzi, para Dewey el autoconocimiento no era el resultado del autoexamen; era la percepción del yo en acción. Pero se trataba de una forma distinta de percepción: una conciencia no de poderes individuales, sino de la existencia del yo como entidad social (Dewey,1984, p. 447), la cual se desarrollaría a partir de las respuestas del medio hacia las acciones del alumno y sus propias respuestas hacia el medio: eso es, a través de lo que Dewey denominó interacción y pensamiento experimental (1997, p. 274). 


\section{Lo interno y lo externo}

Las prácticas pedagógicas del cristianismo institucional introdujeron una división tajante entre el yo interno y el externo que contribuyeron a producir la experiencia moderna de la interioridad; división que era extraña para el pensamiento helenístico, el cual concebía la moralidad como una forma simultánea de actuar de manera deliberada y reflexiva sobre sí y los demás ${ }^{9}$.

El carácter dualista de la concepción de moralidad que dominó en el discurso pedagógico desde el siglo XVI se relacionó con prácticas que opusieron, de maneras diversas, las dimensiones internas y externas del sujeto. Esta oposición se escenificó en el discurso pedagógico en relación con dos problemas centrales: el problema sobre si enfatizar las disposiciones íntimas o públicas del yo; y el problema de sí centrarse en las acciones introspectivas del alumno sobre sí mismo o formas extravertidas e indirectas de autocontrol.

A pesar de la reemergencia parcial en los escritos de Comenio de las nociones helenísticas del carácter público de la virtud, el discurso pedagógico de Vives hasta Pestalozzi estuvo dominado por una imagen del yo moral como desapegado e indiferente hacia la esfera pública y el mundo en general. Esto fue, en lo fundamental, el efecto de la recontextualización particular que le dio el discurso cristiano institucional a las concepciones estoicas de autarkeia y apatheia, la cual ubicó la moralidad y la felicidad por fuera de la esfera colectiva de asuntos mundanos: la fijó en el otro mundo espiritual en el caso de Vives y Comenio y en la privacidad íntima del ser en el caso de Pestalozzi ${ }^{10}$ : mientras que en los estoicos postsocráticos (Séneca, Marco Aurelio), la autodependencia (autarkeia) y la ecuanimidad (apatheia) eran estados del carácter que se requerían para actuar valerosa y honorablemente en la esfera pública, como también para lograr felicidad y libertad personal en esta vida, las diversas formas del discurso pedagógico cristiano se concentraron en la naturaleza sagrada y de renuncia al mundo de estos estados del yo. De otra parte, y a pesar de su intención explícita de superar los dualismos, el

9 Tanto para la caracterización de las prácticas de sí en las sectas filosóficas helenísticas como para sus discontinuidades con las del cristianismo institucional, ver Cordero et al (eds) (2007), Crisipio de Solos (2006) Diógenes Laercio (2007), Eggers et al. (ed.) (2007), Epicuro (2005), Foucault (1987, 1994, 2000b, 2000c, 2000d, 2002, 2009 y 2010) Marco Aurelio (2005), Séneca (1969), Sextus Empiricus (1993), Veyne (1995) y Sáenz (2010).

10 En el otro mundo espiritual en el caso de Vives y Comenio; en la privacidad íntima del ser en el caso de Pestalozzi. 
discurso de Dewey sobre el sujeto ideal fue una continuación de este dualismo entre lo interno y lo externo. Constituyó, en efecto, la inversión de la tradición pedagógica anterior: las virtudes públicas (sociales) fueron sacralizadas en relación con las prácticas de sí, la interdependencia social se ensalzó y la autodependencia fue ridiculizada.

Es a través de las prácticas prescritas a los alumnos en los tratados pedagógicos que este dualismo práctico de Dewey puede verse con mayor claridad. En el discurso cuasimonástico de Vives sobre la constitución de un yo moral y veraz, las acciones morales del alumno se dirigían, primordialmente, hacia acciones sobre sí: el principal requisito para el desenvolvimiento de la verdad era la autopurificación de la mente, que no la acción metódica sobre el mundo. De otra parte, las normas de cortesía eran, principalmente, un medio de autocontrol deliberado, más que una forma de producir efectos sobre los otros. En Comenio, la separación entre acciones sobre sí y sobre el mundo y lo otros adquirieron una nueva forma: las acciones sobre sí se identificaron con la dimensión religiosa y transcendental de la vida, mientras que las acciones extravertidas adquirieron un estatuto más legítimo y autónomo que el que tenían antes, en cuanto acciones morales mundanas. En Pestalozzi y Dewey, las acciones introspectivas deliberadas de los alumnos sobre sí mismos desaparecieron: el yo moral y veraz se convirtió en una develación (Pestalozzi) o construcción (Dewey) por medio de acciones extravertidas.

\section{Moralidad y libertad}

Dentro de la concepción cristiana trascendental compartida por Vives y Comenio, la libertad del yo dejó de ser un fin práctico, como lo había sido en la filosofía helenística: el libre albedrío cristiano es un don divino inherente al ser humano. Su ejercicio no depende de condiciones objetivas específicas; puede desplegarse en medio de una disciplina o gobierno basado en la obediencia, como ha sido el del cristiano institucional, tanto católico como protestante.

Los discursos de Pestalozzi y de Dewey invirtieron la relación entre libertad y moralidad. Mientras que el problema central del cristianismo institucional había sido como hacer un uso virtuoso de la libertad divina, con Pestalozzi el asunto comenzó a girar hacia cómo obtener la suficiente libertad objetiva para poder actuar moralmente. Pero en Pestalozzi y en Dewey la libertad ya no estaba relacionada con las formas en que el yo actuaba deliberadamente sobre si; se convirtió, de manera exclusiva, en el efecto de las interacciones del alumno con el maestro, con otros alumnos, con el método y con el mundo. La libertad adquirió una forma objetiva: se relacionó con las condiciones objetivas, o en palabras de Dewey, con la situación educativa. 


\section{De una moralidad voluntaria a una moralidad involuntaria: de prácticas de sí a auto-coacciones automáticas}

En el discurso pedagógico, se dio otra transformación que en la larga duración debilitó las acciones morales voluntarias y deliberadas sobre sí y empezó a concentrarse en la producción de un alumno moral. Fue con Pestalozzi y el discurso de la Ilustración en general -que, según Maclntyre "incluía tanto una tesis sobre la predictibilidad (...) como sobre las formas apropiadas de manipular la conducta humana" (Maclntyre, 1985, p. 84)que la moralidad se asoció casi que totalmente con las acciones que el alumno llevaba a cabo sin darse cuenta de su naturaleza moral y que no requerían de una deliberación consciente: acciones que se volvían necesarias (eso es, se naturalizaban) por el diseño estratégico de las condiciones pedagógicas. Mientras que en Vives el sujeto moral era producido, en lo fundamental, por sus propias acciones deliberadas y voluntarias -las prácticas del maestro, de vigilancia, castigo y recompensas eran prácticas para fortalecer la voluntad del alumno en función de su autogobierno- en Pestalozzi y Dewey era primordialmente lo que podemos denominar la voluntad escolar, eso es, las acciones estratégicas del maestro y del método, las que producirían un alumno moral. La voluntad, concebida por Vives y Comenio primordialmente como la agencia por medio de la cual el alumno actuaba deliberadamente sobre sí para transformarse, se externalizó. Como parte del proceso de objetivación del sujeto que efectuaron las ciencias humanas desde finales del siglo XIX, el alumno se convirtió en objeto: es decir, se convirtió en blanco de intervenciones, que no en un sujeto que actúa sobre sí.

Las reflexiones anteriores permiten plantear lo siguiente. En la larga duración de los discursos pedagógicos examinados se puede evidenciar el paso de un énfasis evidente en formas deliberadas y voluntarias por medio de las cuales los alumnos debían actuar sobre sí para acceder a la verdad, la moral y la virtud (prácticas de sí) a prácticas por medio de las cuales, de forma excluyente, el alumno se veía obligado a autocoaccionarse de manera involuntaria, no deliberada, automática e inconsciente (las autocoacciones concebidas por Elías, 1994) a partir de las coacciones pedagógicas: eso es, a partir de la forma en que las prácticas de la escuela disciplinaban o regulaban (esto último en el caso de Dewey y en menor medida en Pestalozzi) 
sus interacciones con el maestro, el saber, los otros y las cosas del mundo. Contra Dewey, en esto, hay que decir que no es que las prácticas escolares como las que prescribió, que rechazaban con vehemencia las relaciones que el sujeto establece consigo mismo, hicieran que estas desparecieran en un ámbito social totalizante y sacralizado, sino que las convirtieron en algo automático, inconsciente y habitual, haciendo que, como es característico de las formas liberales de gobernar, el autogobierno se invisibilizara, eso es se naturalizara.

\section{Una hipótesis}

sobre el sentido de la reemergencia contemporánea de las prácticas de sí en la escuela y la pedagogía

Desde hace un par de décadas las prácticas de sí han reaparecido en las escuelas y la pedagogía y también han aparecido en otros ámbitos institucionales: los del nuevo empresarismo, los de los nuevos tratamientos psiquiátricos y de los saberes psi y los de las políticas de salud dirigidas a fomentar el autocuidado, entre otras. En el campo de la pedagogía, se trata de una política impulsada por las agencias multilaterales para enseñar a vivir juntos, para que el alumno aprender a vivir y a "responsabilizarse de sí mismo y realizar su proyecto personal" (Delors, s. f., p. 12). El conjunto de propósitos y prácticas que abarca esta política son presentados como de autogestión de los individuos e incluyen "comprenderse mejor a uno mismo" (p. 12), así como la exploración y regulación de los sentimientos, el desarrollo de sentimientos de autoeficacia, la generación de un pensamiento positivo y prácticas de relajación (Sinclair, 2004, pp. 48-55). Prácticas que, en el caso del documento de política preparado por Margaret Sinclair para la Unesco, se inscriben de manera evidente en la racionalidad propia de la psicología conductista. En Colombia, esta política aparece, de forma más visible e institucional, en las prescripciones del Ministerio de Educación Nacional en los estándares de competencias ciudadanas. Pero, como lo describe Ruth Amanda Cortés (2012, pp. 507-554), para el caso colombiano, a la escuela están entrando también de manera decidida prácticas de sí que denomina como neopastorales, provenientes fundamentalmente del movimiento de autoayuda ${ }^{11}$.

Siguiendo en esto principalmente a Nikolas Rose (1997, 1999, 2007a y 2007b), algunos analistas han señalado que la reemergencia de prácticas de sí de carácter institucional son un efecto de las nuevas modalidades de gobierno del liberalismo avanzado (o neoliberal) de regulación por medio de las cuales los individuos son conducidos a

11 En este párrafo se retoma, con algunas modificaciones y adiciones, lo planteado en un capítulo inédito del autor de este artículo. 
participar en las formas de gobierno hegemónicas, por medio de su autogobierno. Pero esto no dice mucho, no explica por qué reaparecieron: las prácticas de sí son una forma muy específica, entre muchas otras, en que los individuos y la población participan o podrían participar de su propio gobierno. Quisiera entonces proponer algunas ideas sobre este asunto.

Pensaría que el sentido del retorno de las prácticas de sí a las escuelas, luego de su desaparición a partir del siglo XVIII, se relaciona con una preocupación bastante generalizada (un pánico moral en términos de Cohen, 2002) y con un alto grado de resonancia en los medios masivos de comunicación en torno a que, por la crisis de las sociedades contemporáneas, a los niños y jóvenes ya no les estarían enseñando a vivir adecuadamente en sus familias y grupos sociales, por lo que la escuela debe hacerlo. Esto podría pensarse en el marco de una crisis (poco importa si real o percibida) del dispositivo de lo social. Una crisis de los agentes, saberes, instituciones y líneas de fuerza configuradoras de lo social en la modernidad: una crisis, entonces, en términos de Norbert Elías (1994) de las coacciones sociales que, desde la Ilustración, como vimos para el caso de la escuela y la pedagogía, se concebían como generadoras de las necesarias autocoacciones automáticas de un autogobierno involuntario e inconsciente.

Las nuevas formas de gobierno del mercado y de los medios masivos de comunicación no se disponen principalmente hacia las autocoacciones automáticas: se disponen hacia la satisfacción de los intereses, deseos y anhelos inciertos de los individuos y la población, que no a su autocontrol. Habría entonces una desconfianza acerca de que los gobernados efectivamente estén identificando sus intereses, deseos y anhelos inciertos con los de las fuerzas sensatas que los gobiernan, en tanto las fuerzas bárbaras del mercado, la publicidad, los medios comunicativos y tecnológicos masivos, así como las culturas infantiles y juveniles urbanas emergentes estarían configurando de manera más efectiva los intereses y deseos de los individuos y la población, o estos lo estarían haciendo de forma individual y relativamente autónoma, en direcciones inciertas. Crisis entonces de las formas de gobierno contemporáneo que, en esto, rechazan la incertidumbre y buscan apoyarse en la institución moderna por excelencia, en cuanto configuradora principal del sujeto moderno, eso es, del sujeto efectivamente autocoaccionado. Retorno entonces, en esto, a la totalización del gobierno pedagógico cristiano institucional: la escuela ya no solo debe enseñar a pensar disciplinada 
y metódicamente, sino que debe volver a enseñar de manera directa y explícita a vivir: a autorregular sus formas de sentir, imaginar y desear.

Para concluir, hay que ser cuidadosos en la problematización de las prácticas y discursos contemporáneos a partir de análisis genealógicos. Si bien es evidente que, como lo he señalado en este escrito, hay una reemergencia de las prácticas de sí en las escuelas, no puede hablarse del retorno de las prácticas pastorales propias de las formas de gobierno del cristianismo institucional. En este sentido, el término de prácticas neopastorales, acuñado por Ruth Amanda Cortés, es especialmente lúcido, pues permite subrayar solo ciertas continuidades que tienen las prácticas emergentes con las prácticas cristianas: para solo mencionar dos: las relaciones asimétricas con expertos y la manera en que se centran en la dimensión positiva (virtuosa) de lo humano.

Pero, a pesar de estas recurrencias, entre otras, se trata de prácticas de sí claramente diferenciadas de las que hemos examinado en el caso de Vives y Comenio: tanto en el agente de las prácticas como en su objeto o sustancia ética; en sus fines y en las técnicas específicas puestas en juego; en las formas en que los estudiantes son conducidos a emprenderlas y en sus relaciones con prácticas de saber y de poder. Trabajos como la tesis doctoral de Dora Lilia Marín contribuirán a comprender mejor el sentido y alcance de esta reemergencia.

\section{Referencias bibliográficas}

Aristóteles. (1998). The Nicomachean ethics. Oxford: Oxford University Press.

Cohen, S. (2002). Folk devils and moral panics. London and New York: Routledge.

Comenio, J. (1986). Pampaedia or universal education. Dobbie, Dover: Buckland Publications.

Comenio, J. (1907). The great didactic Keatinge, London: Adam and Charles Black.

Comenio, J. (1956). The school of infancy. Chapel Hill: University of North Carolina Press.

Cordero, N. et al. (ed.) (2007). Los filósofos presocráticos. Obras II, Madrid: Gredos.

Cortés, R. (2012). Prácticas de ciudadanización en la escuela contemporánea. Colombia 19842004. (Tesis doctoral). Programa Interinstitucional del Doctorado en Educación. Bogotá. Universidad Pedagógica Nacional.

Crisipio de Solos. (2006). Testimonios y fragmentos I. Madrid: Gredos.

Delors, J. et al. (s. f.). La educación encierra un tesoro. Informe a la Unesco de la educación para el siglo XXI. París: Ediciones Unesco.

Dewey, J. (1972). Ethical principles underlying education. En Dewey, J., The early works, volume 5: 1895-1898 (54-83). Carbondale: Southern Illinois Press.

Dewey, J. (1977a). The moral significance of the common studies, 
1909. En Dewey, J., The middle works, 1899-1924, volume 4: 1907-1909 (205-213). Carbondale: Southern Illinois Press. Dewey, J. (1977b). Moral principles in education, 1909, En Dewey, J., The middle works, volume 4: 1907-1909 (265291). Carbondale: Southern Illinois Press.

Dewey, J. (1984). My pedagogical creed, 1897. En McDermontt, J. (ed.), The philosophy of John Dewey (442-454). Chicago: University of Chicago Press.

Dewey, J. (1997). Democracy and Education. An introduction to the philosophy of education, 1916, New York: The Free Press.

Diógenes Laercio. (2007). Vida de los filósofos ilustres. Madrid: Alianza Editorial.

Eggers, C. et al. (ed.) (2007). Los filósofos presocráticos. Obras I. Madrid: Gredos.

Elías, N. (1994). The civilizing process. The history of manners and state formation and civilization. Oxford: Blackwell.

Epicuro. (2005). Obras. Madrid: Tecnos.

Foucault, M. (1977). "Truth and power", En Foucault, M. Power. Essential works of Foucault 1954-1984, vol.3, 2000 (111133). London: Penguin.

Foucault, M. (1979). Discipline and punish. The birth of the prison. London: Penguin.

Foucault, M. (1987). La inquietud de sí. Historia de la sexualidad 3. México: Siglo XXI Editores.

Foucault. M. (1992). The use of pleasure. The history of sexuality: 2. London: Penguin.

Foucault, M. (2000a). On the government of the living. En Foucault, M., Ethics. Essential works of Foucault 1954-1984 (8186). London: Penguin.

Foucault, M. (2000b). Foucault. En Foucault, M., Aesthetics. Essential works of Foucault 1954-1984 (459-464). London: Penguin.

Foucault, M. (2000c). Technologies of the self. En Foucault, M., Ethics. Essential works of Foucault 1954-1984 (223-252). London: Penguin.

Foucault, M. (2000d). On the genealogy of ethics. En Foucault, M., Ethics. Essential works of Foucault 1954-1984 (255-280). London: Penguin.

Foucault, M. (2000e). Truth and power. En Foucault, M., Power. Essential works of Foucault 1954-1984 (11-133). London: Penguin. 
Foucault, M. (2002). La hermenéutica del sujeto. Curso en el Collège de France 1981-1982. México: Fondo de Cultura Económica.

Foucault, M. (2009). El gobierno de sí y de los otros. México: Fondo de Cultura Económica.

Foucault, M. (2010). El coraje de la verdad. México: Fondo de Cultura Económica.

Hyma, A. (1965). A Christian Renaissance. A history of the Devotio Moderna. Jamden: Anchor Books.

Komensky, J. (1953). The analytical didactic of Comenius (Didaktika analytická). Chicago: University of Chicago Press.

MacIntyre, A. (1985). After virtue. A study in moral theory, London: Duckworth.

Malaise, J. ((1988). Introduction. Gerard Groote and the Following of Christ. En Groote, G., The Following of Christ (XIXIV). Rockford: Tan Books and Publishers.

Marco Aurelio. (2005). Meditaciones, Madrid: Ediciones Cátedra.

Morey, M. (1996). Introducción. La cuestión del método. En Foucault, M., Tecnologías del yo y otros textos afines. Barcelona: Paidós.

Pestalozzi, J. (1907). How Gertrude teaches her children, 1801. En Cooke, E. (ed.), How Gertrude teachers her children. An attempt to help mothers to teach their own children and An account of the method (1-197). London: Swan Sonnenschein.
Pestalozzi, J. (1913). Letter from Stanz, 1807, (selections). En Life and work of Pestalozzi (7285). London: University Tutorial Press.

Pestalozzi, J. (1931). Articles in the Swiss News, 1782, (selections). En Anderson, L. (ed.), Pestalozzi (35-47). London: McGraw-Hill Publishing.

Pestalozzi, J. (1982). El canto del cisne. México: Editorial Porrúa.

Pestalozzi, J. (1827). Letters on early education addressed to J.P. Greaves, Esq. By Pestalozzi. London, Sherwood: Gilbert and Piper.

Rose, N. (1997). El gobierno en las democracias liberales avanzadas: del liberalismo al neoliberalismo. Revista Archipiélago, 29.

Rose, N. (1999). Governing the soul. The shaping of the private self, London: Free Association Books.

Rose, N. (2007a). The politics of life itself. Biomedicine, power and subjectivity in the twenty-first century. Princeton: Princeton University Press.

Rose, N. (2007b). ¿La muerte de lo social? Re-configuración del territorio de gobierno. Revista Argentina de Sociología, 5(8), 111-150.

Sáenz Obregón. J. (2007). La escuela como dispositivo estético. En Frigerio, G y Diker, G. (comp.), Educar (sobre)impresiones estéticas. Buenos Aires: Del Estante Editorial.

Sáenz Obregón, J. (2009). Formación: infantilización y autocreación. En Martínez, J. y Orlando 
F. (ed.), Miradas sobre la subjetividad. Bogotá: Universidad de la Salle.

Sáenz Obregón, J. (2010). Notas para una genealogía de las prácticas de sí. Conferencia para la candidatura como profesor titular, Universidad Nacional de Colombia. Recuperado de www.saenzjavier.blogspot.com

Séneca. (1969). Letters from a stoic. London: Penguin Classics. Sextus Empiricus. (1993). Esbozos pirrónicos. Madrid: Gredos.

Sinclair, M. (2004). Learning to live together: building skills, values and attitudes for the twenty-first century. Ginebra: International Bureau of Education, Unesco.

Veyne, P. (1995). Séneca y el estoicismo. México: Fondo de Cultura Económica.

Vives, J. (1913). Vives: On education. A Translation of "De tradendis disiplinis" of Juan Luis Vives. Cambridge: Cambridge University Press.

Vives, J. (1948). Tratado del alma (De anima et vita). En Vives, J., Obras completas, tomo 2, 1149-1319. Madrid: M. Aguilar Editor.

Vives, J. (1968). Introduction to Wisdom (Introductio ad sapientiam). En Tobriner, M. (ed.), Vives' Introduction to Wisdom (77-159). New York: Teachers College, Columbia University. Zuluaga, O. (1987). Pedagogía e historia. Bogotá: Ediciones Foro Nacional por Colombia. 